\title{
Cytomorphological Study of Thyroid Lesions Using the Bethesda System for Reporting Thyroid Cytology and Its Correlation with Thyroid Function Test
}

\author{
Trusha Thakor ${ }^{1}$, Meena Rajiv Daveshwar², Hiral Samir Shah ${ }^{3}$ \\ ${ }^{1}$ Department of Pathology, SSG Hospital and Medical College, Baroda, Gujarat, India. \\ ${ }^{2}$ Department of Pathology, SSG Hospital and Medical College, Baroda, Gujarat, India. \\ ${ }^{3}$ Department of Pathology, SSG Hospital and Medical College, Baroda, Gujarat, India.
}

\section{ABSTRACT}

\section{BACKGROUND}

Fine-needle aspiration cytology of thyroid is a simple, minimally invasive, cost effective, readily available, reliable, time saving and an easy to perform outpatient procedure. ${ }^{1}$ The Bethesda System for Reporting Thyroid Cytopathology (TBSRTC) is a six category scheme of thyroid cytopathology reporting. ${ }^{2}$ FNAC in conjunction with thyroid hormonal profile helps in assessing stage of the disease as hyperthyroid, hypothyroid or euthyroid ${ }^{3}$. It is very helpful in deciding the treatment options for the patient.

\section{METHODS}

This is a prospective study of 125 fine needle aspirations (FNA) of thyroid nodules. All fine needle aspiration cytology (FNAC) diagnosis were classified according to age and gender, cytological findings and TBSRTC categories. All TBSRTC categories were correlated with thyroid function test results.

\section{RESULTS}

The distribution of various categories from 125 evaluated thyroid nodules was as follows: $6.4 \%$ Non-Diagnostic or Unsatisfactory (ND/UNS), $80 \%$ benign, $2.4 \%$ Atypia of Undetermined Significance or Follicular Lesion of Undetermined Significance (AUS/FLUS), 4\% Follicular Neoplasm (FN), 4\% Suspicious for Malignancy (SFM), and 3.2\% Malignant. Maximum cases with altered TFT were found in category II. Whereas in category V (5/5) \& in category VI (4/4), all cases were euthyroid \& not a single case of altered Thyroid Function Test (TFT) was found. Among the 16 cases of thyroiditis, majority of the cases was hypothyroid.

\section{CONCLUSIONS}

TBSRTC is an excellent reporting system for thyroid FNA. It also provides clear management guidelines to clinicians to go for follow-up FNAC or surgery. Diagnostic challenges arise when aspirate samples are quantitatively or qualitatively suboptimal and, in such situations, clinical and TFT correlations are immensely helpful. Alteration in thyroid function tests is associated with benign conditions mostly in thyroiditis in which hypothyroid state can aid in the diagnosis of the benign lesions.

\section{KEY WORDS}

Fine Needle Aspiration Cytology (FNAC), Thyroid, Thyroid Function Test, The Bethesda System for Reporting Thyroid Cytology (TBSRTC)
Corresponding Author: Dr. Meena Rajiv Daveshwar, 18, Yantrika Society, Near Chanakyapuri, New Sama Road, Vadodara-390024, Gujarat, India.

E-mail: mrdaveshwar@gmail.com

DOI: $10.14260 /$ jemds/2020/204

Financial or Other Competing Interests: None.

How to Cite This Article:

Thakor T, Daveshwar MR, Shah HS. Cytomorphological study of thyroid lesions using the bethesda system for reporting thyroid cytology and its correlation with Thyroid Function Test. J. Evolution Med. Dent. Sci. 2020;9(12):949-952, DOI: $10.14260 /$ jemds/2020/204

Submission 18-12-2019,

Peer Review 02-03-2020,

Acceptance 09-03-2020,

Published 23-03-2020.

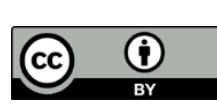




\section{BACKGROUND}

Fine-needle aspiration cytology of thyroid is a simple, minimally invasive, cost effective, readily available, reliable, time saving and an easy to perform outpatient procedure. Because of this, FNAC has become the diagnostic tool of choice for the initial evaluation of solitary thyroid nodules, and therefore has reduced the number of patients undergoing thyroid surgery for benign diseases like thyroiditis, with resultant decrease in the cost of health care.

FNAC of thyroid is a widely accepted as the most accurate procedure to differentiate neoplastic from non-neoplastic lesions which can lead to correct management decisions and prevents unnecessary thyroidectomies. ${ }^{1}$ It is crucial that cytopathologist communicate thyroid FNA interpretation to referring physicians in terms that are clear, unambiguous and clinically helpful. However due to lack of a standardized system of reporting, there is confusion among clinicians in the correct interpretation of the report. To address terminology and other issues related to thyroid FNA, in 2007 the National Cancer Institute (NCI) hosted the Thyroid Fine Needle Aspiration State of Science Conference in Bethesda, Maryland. Subsequently NCI published a monograph entitled "The Bethesda System for Reporting Thyroid Cytopathology (TBSRTC)", which included definition, diagnostic and morphologic criteria, explanatory notes and a brief management plan for each diagnostic category. 2,4

TBSRTC is a six-category scheme of thyroid cytopathology reporting. These include non-diagnostic / unsatisfactory, benign, Atypia of Undetermined Significance or Follicular Lesion of Undetermined Significance (AUS/FLUS), suspicious for follicular neoplasm (SFN), suspicious for malignancy(SM) and malignant. Each category has an implied cancer risk which ranges from $0 \%$ to $3 \%$ for the benign category to virtually $100 \%$ for the malignant category. ${ }^{2,5}$ Thyroid diseases may be classified on the basis of hormone profile as hyperthyroid, hypothyroid and euthyroid. Various thyroid diseases can have either of the above status at different stages of the disease development in the same patient. In majority of the patients, symptoms are subtle in presentation. So use of FNAC in conjunction with thyroid hormonal profile helps in assessing the stage of the disease and deciding the treatment option for the patient.

The objectives of this study were to study cytomorphological features of thyroid lesions, to classify thyroid cytology smears in six categories by using TBSRTC criteria, to convey brief management plan to clinicians and in addition the categories were correlated with thyroid hormonal status.

\section{METHODS}

The study was carried out at the cytology section, Pathology department, S. S. G. Hospital and Medical College Baroda. It was time bound study conducted from November 2017 to October 2018 and consisted of total of 125 cases. Thorough clinical examination including detailed history, general examination and local examination of thyroid gland was performed. The findings were recorded along with Thyroid Function Test (TFT) results (T3, T4, TSH). TFT details were obtained from Biochemistry department of S.S.G. Hospital, Vadodara. Patients were explained about FNA and consent for performing the procedure was taken.

FNA was performed with 23 Gauge needle attached to a $10 \mathrm{cc}$ disposable syringe. In cases of unsatisfactory smears repeat FNA was done under ultrasonography guidance. Wet smears were immediately fixed with 95\% methanol and stained with Haematoxylin \& Eosin and pap stain. The smears intended for Giemsa stain were allowed to air dry and quickly fixed with methanol and stained with Giemsa. The cytological features were evaluated, and the reporting was done according to the morphological criteria given in the monograph of TBSRTC.

\section{Statistical Analysis}

Statistical data analysis was done by descriptive statistics for percentage of different types of TBSRTC categories and age and sex distribution in the form of mean, range, standard deviation, ratio and proportion.

\section{RESULTS}

Among the 125 thyroid FNAC cases studied, the age range was from 11 to 85 years with the maximum number of cases in the age group of $41-50$ years ( 36 cases; $28.8 \%$ ). The mean age was 39.64 years. 105 patients (84\%) were females and 20 patients (16\%) were males. Male: Female ratio was 1:5.3. Out of 125 cases studied, the maximum numbers of cases were in category $\mathrm{II}(80 \%)$ while minimum number of cases were in category III(2.4\%). In category II, majority of cases were Benign thyroid lesion (Colloid nodule/ Adenomatoid nodule) accounting for $84 / 100$ cases followed by Lymphocytic/Hashimoto's thyroiditis (14/100) and Granulomatous thyroiditis with 2/100. When only cyst fluid was aspirated without cellularity or colloid, the cases were categorised in Category I (6.4\%).5/125 cases showed highly cellular smear consisting of uniform follicular cells in crowded clusters and micro follicles diagnosed as Follicular Neoplasm (TBSRTC IV). In Category VI, 4/125 cases (3.2\%) were malignant lesions where 3 cases were diagnosed as papillary thyroid carcinoma and the remaining 1 case as Follicular Variant of Papillary Thyroid Carcinoma (Table 1).

\begin{tabular}{|c|c|c|c|c|c|c|c|}
\hline \multicolumn{4}{|c|}{ TBSRTC Category } & \multicolumn{2}{|c|}{ No. of Cases } & \multicolumn{2}{|c|}{ Percentage } \\
\hline \multicolumn{4}{|c|}{ Category I (Non diagnostic) } & & 08 & \multicolumn{2}{|c|}{$6.4 \%$} \\
\hline \multicolumn{5}{|c|}{ Category II (Benign) } & 100 & \multicolumn{2}{|c|}{$80 \%$} \\
\hline \multirow{2}{*}{\multicolumn{5}{|c|}{$\begin{array}{c}\text { Category III (Atypia of Undetermined significance) } \\
\text { Category IV (follicular neoplasm) }\end{array}$}} & 03 & \multicolumn{2}{|c|}{$2.4 \%$} \\
\hline & & & & & 05 & \multicolumn{2}{|c|}{$4.0 \%$} \\
\hline \multirow{2}{*}{\multicolumn{5}{|c|}{$\begin{array}{l}\text { Category V (suspicious for malignancy) } \\
\text { Category VI (malignant) }\end{array}$}} & 05 & \multicolumn{2}{|c|}{$4.0 \%$} \\
\hline & & & & & 04 & \multirow{2}{*}{\multicolumn{2}{|c|}{$\begin{array}{c}3.2 \% \\
100 \% \\
\end{array}$}} \\
\hline \multicolumn{4}{|c|}{ Total } & & 125 & & \\
\hline \multicolumn{8}{|c|}{$\begin{array}{c}\text { Table 1. Distribution of Cases According to } \\
\text { TBSRTC in the Present Study }\end{array}$} \\
\hline \multicolumn{8}{|c|}{ TBSRTC Categories } \\
\hline 151 & I & II & III & IV & V & VI & Total \\
\hline Euthyroid & 05 & 43 & 02 & 03 & 05 & 04 & 62 \\
\hline Hyperthyroid & 00 & 20 & 01 & 00 & 00 & 00 & 21 \\
\hline Hypothyroid & 03 & 37 & 00 & 02 & 00 & 00 & 42 \\
\hline Total & 08 & 100 & 03 & 05 & 05 & 04 & 125 \\
\hline
\end{tabular}




\begin{tabular}{|ccccccc|}
\hline Study & I (\%) & II (\%) & III (\%) & IV (\%) & V (\%) & VI (\%) \\
Singh et al & 13.2 & 41.3 & 3.7 & 5.6 & 3.9 & 4.5 \\
Muratli et al & 10.8 & 59.5 & 8.7 & 0.6 & 2.8 & 17.6 \\
Naz et al & 4.7 & 76.3 & 12.7 & 2.1 & 3.4 & 0.8 \\
Mehrotra et al & 4.57 & 68.58 & 5.72 & 17.14 & 1.14 & 2.85 \\
Yasmeen Khatib et al & 0.68 & 88 & 3.4 & 4.5 & 1.4 & 2.06 \\
Present study & 6.4 & 80 & 2.4 & 4.0 & 4.0 & 3.2 \\
\hline Table 3. Comparison of Distribution of Cases of \\
Various Studies According to TBSRTC \\
\hline \multicolumn{7}{c}{}
\end{tabular}

\begin{tabular}{|c|c|c|c|c|c|c|c|c|}
\hline \multirow{3}{*}{$\begin{array}{l}\text { Hormonal } \\
\text { Status }\end{array}$} & \multirow{3}{*}{ Studies } & \multirow{2}{*}{\multicolumn{6}{|c|}{$\begin{array}{l}\text { Distribution According to } \\
\text { TBSRTC Category }\end{array}$}} & \multirow{3}{*}{ Total } \\
\hline & & & & & & & & \\
\hline & & I & II & III & IV & V & VI & \\
\hline \multirow{3}{*}{$\begin{array}{l}\text { Euthyroid } \\
\text { status }\end{array}$} & Yasmeen Khatib et al & 00 & 146 & 10 & 11 & 05 & 06 & $178 / 285$ \\
\hline & & 03 & 25 & 00 & 06 & 00 & 00 & \\
\hline & & 05 & 43 & & 3 & 05 & 04 & 62 \\
\hline \multirow{3}{*}{$\begin{array}{l}\text { Hyperthyroid } \\
\text { status }\end{array}$} & Yasmeen Khatib et al & 00 & 43 & 00 & 00 & 00 & 00 & $43 / 285$ \\
\hline & & 00 & 08 & 00 & 03 & 00 & 00 & $11 / 69$ \\
\hline & & 00 & 20 & 01 & 00 & 00 & 00 & $21 / 125$ \\
\hline \multirow{3}{*}{$\begin{array}{l}\text { Hypothyroid } \\
\text { status }\end{array}$} & Yasmee & 00 & 63 & 00 & 01 & 00 & 00 & $64 / 285$ \\
\hline & & 01 & 15 & 03 & 03 & 00 & 02 & $24 / 69$ \\
\hline & Present study & 03 & 37 & 00 & 02 & 00 & 00 & $42 / 125$ \\
\hline
\end{tabular}

Maximum number of cases with altered TFT were found in category II. In contrast category V and VI did not have single case of altered TFT (Table 2). In category II, among the 16 cases of thyroiditis (14 of lymphocytic/Hashimoto's' thyroiditis, 2 of granulomatous thyroiditis) majority were hypothyroid (8/16). While among 84 cases of benign thyroid Lesion, majority were $(37 / 84)$ euthyroid.

\section{DISCUSSION}

Fine needle aspiration cytology is regarded as the gold standard initial investigation in the diagnosis of thyroid lesions. When coupled with clinical findings like age, sex, ultrasonography and thyroid function tests the diagnostic accuracy of the procedure improves greatly. The standard nomenclature of The Bethesda System is to improve communication between the pathologist and surgeon in deciding the treatment modality for the patients and avoid unnecessary surgeries. It was easy to classify the results in the six categories as opposed to earlier reporting system. The mean age in the present study was 39.64 years, which correlates well with the study conducted by $\mathrm{Naz}$ et $\mathrm{al}^{6}$ and Mehrotra et $\mathrm{al}^{7}$ where the mean age at presentation was 39.7 years and 36.29 years respectively. The Male: Female ratio in the present study was $1: 5.3$, which correlates well with the study conducted by Singh et $\mathrm{al}^{8}$ and Muratli et $\mathrm{al}^{9}$ who reported a Male: Female ratio of 1:4.7 and 1:4.8 respectively.

The distribution of cases according TBSRTC categories, obtained in present study was compared with the various studies (Table 3). There was wide range of variation in category I cases. This could be attributed due to technique of FNA as well as inherent nature of the lesion (e.g., solid vs. cystic).However proper training for technique can lower down number of cases in this category. Maximum number of cases were in benign category which was similar in all the other studies. Bethesda system recommend a limited use of category III AUS and not more than $7 \%$ cases should be included in this group there is a variation in this category because it is somewhat heterogeneous and subjective. Repeat
FNA and follow-up is recommended management for this category. However, in our setup all cases were operated. Though FNAC can provide an accurate diagnosis in majority of cases, there are problems in the indeterminate categories of AUS/FLUS and Suspicious for Follicular Neoplasm. In these cases, molecular testing for somatic mutations like BRAF, RAS, RET/PTC and PAX8/PPARy can complement the cytology findings, leading to better management decision. ${ }^{10}$

Thyroid function tests were performed in all cases and distributed along with TBSRTC and compared with Yasmeen Khatib et al and Mehrotra et al. ${ }^{7}$ In TFT most sensitive is TSH level. Whereas total T3 and total T4 are altered in other nonthyroid illness. So, in the present study cases were distributed in euthyroid, hypo and hyperthyroidism according to TSH level and this findings were compared with other 2 studies (Table 4 . They were altered in majority (63) cases of benign lesions while only $1 / 3$ of AUS category (Category III) was hyperthyroid and $2 / 5$ cases of category IV were hypothyroid. Rest of cases of category III and IV cases as well as all cases from category V and VI were euthyroid. Hyperplastic nodules are characterized by the presence of variable cellular patterns varying from honeycomb or follicular arrangement to singly scattered thyroid follicular cells. These cells display scant to abundant (oncocytic change), mildly vacuolated cytoplasm and small dark staining nuclei. Watery colloid with cytoplasmic thyroglobulin blebs may also be seen. In certain cases, the presence of features like nuclear grooves, chromatin clearing with overlapping of nuclei might create diagnostic dilemma so in these cases TFT level is very useful which is mostly elevated.

The most commonly described pitfall in diagnosing papillary carcinoma is the presence of cyst along with papillary carcinoma. However, presence of co-existent papillary carcinoma and nodular colloid goiter without cystic change causing difficulty in diagnosis on cytology alone. This is because of the occult papillary carcinoma, which was masked by the nodular goiter which formed the major bulk of the swelling. These kinds of lesions require a high degree of suspicion and careful examination of nuclear features in long standing goiter cases. In present study, patients were not able to undergo all diagnostic tests owing to economic and social reasons. None of the cases underwent a thyroid scan or antibody panel analysis because of unavailability of tests in the hospital. However, in spite of the limited resources there was a high satisfactory rate of FNAC smears.

The ability of FNAC of thyroid reporting by TBSRTC to differentiate benign from malignant lesions, with the exception of follicular neoplasm which requires demonstration of capsular and /or vascular invasion, which cannot be evaluated on cytology, aids in deciding the management algorithm with the biochemical tests helping in making a decision on the use of combined medical and surgical modalities in individual cases. Majority cases of thyroiditis were hypothyroid (8/16) followed by euthyroid (6/16) and 2 cases were hyperthyroid. The findings were similar to Yasmeen Khatib et al (37/68 were hypothyroid) and Mehrotra et $\mathrm{al}^{7}$ (8/12 were hypothyroid). Whereas in BTL majority cases were euthyroid (37/84) which was also similar to Yasmeen Khatib et al and Mehrotra et al. ${ }^{7}$ 


\section{CONCLUSIONS}

To cater to the needs of universal terminology in thyroid cytology and for better communication between the pathologist and the surgeon, Bethesda System for Reporting Thyroid Cytology is the gold standard. The classification of thyroid FNA smears into the Bethesda categories is a simple, convenient and a standardized method of reporting which also provides management guidelines. Diagnostic challenges arise when aspirate samples are quantitatively or qualitatively suboptimal to reliably exclude a neoplastic process. In such situations, clinical, TFT, USG correlations are immensely helpful. Alteration in thyroid function tests is associated with benign conditions mostly in thyroiditis with hypothyroid state which can aid in the diagnosis of the benign lesions with atypical features.

\section{REFERENCES}

[1] Esmaili HA, Taghipour H. Fine-Needle aspiration in the diagnosis of thyroid diseases: an appraisal in our institution. ISRN Pathology 2012;2012:912728.

[2] Hoda RS. The Second edition Bethesda system for reporting thyroid cytopathology. In: Hoda R, Rao R, Scognamiglio T, eds. Atlas of Thyroid cytopathology on liquid-based preparations. Springer, Cham 2020: p. 23-6.

[3] Khatib Y, Mulla A, Patel RD, et al. Classification of thyroid FNA smears into Bethesda categories and their correlation with thyroid function tests. Sch J App Med Sci 2016;4(3D):916-23.
[4] Wu CW, Dionigi G, Lee KW, et al. Calcifications in thyroid nodules identified on preoperative computed tomography: patterns and clinical significance. Surgery 2012;151(3):464-70.

[5] Rosen JE, Stone MD. Contemporary diagnostic approach to the thyroid nodule. Journal of Surgical Oncology 2006;94(8):649-61.

[6] Naz S, Hashmi AA, Khurshid A, et al. Diagnostic accuracy of Bethesda system for reporting thyroid cytopathology: an Institutional perspective. International Archives of Medicine 2014;7:46.

[7] Mehrotra D, Anita AM, Sainath K. et al. Thyroid cytology evaluation based on the Bethesda system with clinicomorphological correlation. Annals of Pathology and Laboratory Medicine 2016;3(4).

[8] Singh RS, Wang HH. Eliminating the "atypia of undetermined significance/follicular lesion of undetermined significance" category from the Bethesda system for reporting thyroid cytopathology. Am J Clin Pathol 2011;136(6):896-902.

[9] Muratli A, Erdogan N, Sevim S, et al. Diagnostic efficacy and importance of fine needle aspiration cytology of thyroid nodules. Journal of Cytology 2014;31(2):73-7.

[10] Agarwal S, Rao RS, Parikh DM, et al. Histologic trends in thyroid cancer 1969-1993: a clinico-pathologic analysis of the relative proportion of anaplastic carcinoma of the thyroid. J Surg Oncol 1996;63(4):251-5. 